RESEARCH REPORT

\title{
Association between ambient air pollution and birth weight in São Paulo, Brazil
}

\author{
N Gouveia, S A Bremner, H M D Novaes
}

J Epidemiol Community Health 2004;58:11-17

See end of article for authors' affiliations

Correspondence to:

Dr N Gouveia,

Departamento de

Medicina Preventiva,

Faculdade de Medicina da

Universidade de São

Paulo-FMUSP, Av Dr

Arnaldo, 455, São Paulo-

01246-903-SP-Brazil;

ngouveia@usp.br

Accepted for publication

27 May 2003
Objectives: Previous studies have implicated air pollution in increased mortality and morbidity, especially in the elderly population and children. More recently, associations with mortality in infants and with some reproductive outcomes have also been reported. The aim of this study is to explore the association between exposure to outdoor air pollution during pregnancy and birth weight.

Design: Cross sectional study using data on all singleton full term live births during a one year period. For each individual birth, information on gestational age, type of delivery, birth weight, sex, maternal education, maternal age, place of residence, and parity was available. Daily mean levels of $\mathrm{PM}_{10}$, sulphur dioxide, nitrogen dioxide, carbon monoxide, and ozone were also gathered. The association between birth weight and air pollution was assessed in regression models with exposure averaged over each trimester of pregnancy.

Setting: São Paulo city, Brazil

Results: Birth weight was shown to be associated with length of gestation, maternal age and instruction, infant gender, number of antenatal care visits, parity, and type of delivery. On adjusting for these variables negative effects of exposure to $\mathrm{PM}_{10}$ and carbon monoxide during the first trimester were observed. This effect seemed to be more robust for carbon monoxide. For a 1 ppm increase in mean exposure to carbon monoxide during the first trimester a reduction of $23 \mathrm{~g}$ in birth weight was estimated. Conclusions: The results are consistent in revealing that exposure to air pollution during pregnancy may interfere with weight gain in the fetus. Given the poorer outlook for low birthweight babies on a number of health outcomes, this finding is important from the public health perspective.
$\mathrm{T}$ here is mounting evidence that ambient levels of air pollution have adverse effects on human health. Studies conducted in a wide range of cities with contrasting levels of air pollution have reported effects such as increased mortality and morbidity from different causes and in various age groups. ${ }^{1}$ There are also indications that these effects are higher for more vulnerable subgroups such as the elderly population and children. ${ }^{2-4}$ In addition, some other studies have found significant associations between air pollutants and perinatal mortality. ${ }^{56}$

More recently, a study conducted in São Paulo, Brazil, found an association between air pollution and intrauterine mortality or late fetal losses (28 weeks or more into gestation). ${ }^{7}$ This study also showed that umbilical cord blood levels of carboxyhaemoglobin were correlated with ambient levels of carbon monoxide (CO) bringing evidence of fetal exposure to outdoor levels of air pollution.

If environmental factors such as air pollution affect the health of very young children and even unborn babies it seems reasonable to hypothesise that it may also have an effect on intrauterine growth. Thus, air pollution acting on pregnant women could affect fetal development contributing to a variety of undesirable reproductive outcomes such as preterm delivery, birth defects or low birth weight.

To date, few studies have attempted to explore the relation between air pollution and low birth weight (defined as $<2500 \mathrm{~g}$ ). An ecological study in the Czech Republic found that the prevalence of low birth weight was significantly associated with air pollution, especially sulphur dioxide $\left(\mathrm{SO}_{2}\right) \cdot{ }^{8}$ In China, particulates and $\mathrm{SO}_{2}$ were associated with birth weight after adjusting for maternal, fetal and pregnancy characteristics. ${ }^{9}$ Another study in the Czech Republic found that exposure to air pollution in the first trimester of pregnancy was related to a higher risk of low birth weight. ${ }^{10}$
A study in California showed evidence of an effect on birth weight of exposure to particles and CO in late pregnancy. ${ }^{11}$ In another study in six US cities, relations between low birth weight and $\mathrm{CO}$ and $\mathrm{SO}_{2}$ were found..$^{12}$ In Seoul, South Korea, $\mathrm{CO}$, nitrogen dioxide $\left(\mathrm{NO}_{2}\right), \mathrm{SO}_{2}$ and total suspended particle concentrations (TSP) in the first trimester of pregnancy were considered risk factors for low birth weight in full term infants. ${ }^{13}$ A population based case-control study in Georgia, USA suggested an association between very low birth weight $(<1500 \mathrm{~g})$ and maternal exposure to high levels of air pollution. ${ }^{14}$

Low birth weight is one of the most important predictors of infant health and is a significant determinant of neonatal and postneonatal mortality. ${ }^{15}$ Recent studies have shown that infants who are smallest at birth have a higher incidence of diseases and disabilities, which continue into adulthood. ${ }^{16}$

Birth weight is primarily determined by gestational age and intrauterine growth. It depends on maternal, placental and fetal factors as well as on environmental and constitutional influences. Among known risk factors for a low birthweight baby, maternal age, parity, pre-pregnancy weight, history of adverse pregnancy outcomes, social class, and cigarette smoking are the most commonly reported. ${ }^{15}{ }^{17}$

A recent study conducted in São Paulo, Brazil, a city with notably high levels of air pollution, found that rates of low birthweight babies have hardly changed in the past 20 years and are still considerably high despite improvements in access to health services and maternal education. ${ }^{18}$ Similar

Abbreviations: $\mathrm{CO}$, carbon monoxide; $\mathrm{SO}_{2}$, sulphur dioxide; $\mathrm{NO}_{2}$, nitrogen dioxide; TSP, total suspended particle; $\mathrm{O}_{3}$, ozone; GAM, generalised additive models 


\section{Key points}

- Air pollution seems to adversely affect the placenta and fetus during pregnancy

- Children born to mothers with higher exposure to air pollution are more likely to weigh less than expected in given conditions

patterns have also been observed in other countries, including developed ones. In the US, increasing trends of low birth weight and preterm birth for black and white infants were observed between 1981 to $1998 .{ }^{19}$ These observations indicate the need for additional and specific research into possible causes of low birth weight including little explored risk factors, such as air pollution.

Considering the hypothesis of high levels of pollution interfering with fetal growth, through still unknown mechanisms, and the possibility of estimating intra-uterine growth retardation through the prevalence of low birth weight ${ }^{20}$ and the high levels of air pollution in São Paulo, we hypothesised that the lack of decline in low birthweight rates during the past 20 years could have been influenced by the high levels of air pollution in the city that have remained stable throughout the same period. Therefore, we carried out a study to examine if there is an association between maternal exposure to outdoor levels of air pollution during pregnancy and birth weight in the city of São Paulo.

\section{METHODS}

Data on live births were obtained from the Birth Information System (SINASC) of the Ministry of Health in Brazil. According to this system every live birth is expected to result in a certificate, which is later requested for legal registration of the child. These certificates are captured on local registers and sent to the State Office for Statistics where they are compiled.

For each individual birth, information from these certificates is available on maternal age, maternal education, place of residence, parity, number of antenatal care visits, type of pregnancy ( single, double, triple or more), length of gestation in weeks, date of birth, site of birth (home, hospital or other health service), method of delivery (spontaneous, surgical or forceps), Apgar scores, birth weight, and sex.

According to recent evaluations this information system is considered to be adequate and capable of providing good quality information for the main variables, especially for the city of São Paulo. ${ }^{21}$ All births to mothers resident in the city of São Paulo during 1997 were obtained from this register.

Data on air pollution were available from CETESB, the environmental agency in São Paulo. These data comprised daily means (24 hour averages) of $\mathrm{SO}_{2}$ and respirable particles $\left(\mathrm{PM}_{10}\right)$, the maximum hourly mean calculated during the 24 hour period for $\mathrm{NO}_{2}$ and ozone $\left(\mathrm{O}_{3}\right)$, and the maximum eight hour moving average for $\mathrm{CO}$. These data were collected from a minimum of four monitoring sites (CO) and a maximum of 12 sites $\left(\mathrm{PM}_{10}\right.$ and $\left.\mathrm{SO}_{2}\right)$. For each pollutant, as inter-site correlation was high, daily citywide levels were calculated by averaging all available data across all monitoring stations. The attainments of the network of monitoring stations and the data handling capabilities of CETESB have been considered to be of high quality. ${ }^{22}$

The analysis of the relation between birth weight and air pollution was carried out only for live singleton full term pregnancies ( $\geqslant 37$ weeks of gestation). Birth weight was considered in separate analyses as a (1) continuous and as a
(2) binary variable taking the values of 1 for birth weight of less than $2500 \mathrm{~g}$ and 0 otherwise.

Maternal exposure to air pollution at each trimester of the pregnancy was estimated taking into account the date of birth and the length of each gestation. Mean exposures of about three months to each air pollutant were then assigned to each birth. Logistic regression was used to identify maternal and pregnancy factors associated with low birth weight.

By way of regression using GAM models ${ }^{23}$ to allow for the non-linear effect of maternal age on birth weight we assessed the change in birth weight associated with the mean exposure to air pollution during each trimester of pregnancy adjusting for the factors related to low birth weight. We used logistic regression to estimate the odds of having a low birthweight baby according to maternal exposure while adjusting for the same factors. Single and multiple pollutant models were examined. All analyses were carried out in SPlus 2000 (Mathsoft, Seattle, WA). Care was taken in relation to the model convergence criteria and in computing exact standard errors of the pollutant estimates. ${ }^{24}$

\section{RESULTS}

There were 214973 live births to mothers resident in the city of São Paulo during 1997. Of these, 196978 (91.6\%) were singleton pregnancies with complete information for gestational age. Pre-term live births accounted for $6.2 \%$ of these pregnancies and were excluded from the analysis. In addition, we decided to further exclude very low $(<1000 \mathrm{~g})$ and very high $(>5500 \mathrm{~g})$ birthweight babies as we assumed that those babies were very likely to be the product of high risk pregnancies. Thus, any possible effect of air pollution on those pregnancies would be outweighed by other high risk conditions. This resulted in a population of 179460 live births for the final analysis.

Figure 1 shows the daily mean birth weight during 1997 in São Paulo. Although our data were restricted to just one year, it can be observed that birth weight exhibited a seasonal pattern. This was confirmed by the descriptive analysis of birth weight in table 1 , which also depicts the seasonal pattern of air pollution during the period of this study.

The mean birth weight, the proportion of low birthweight babies and adjusted odds ratios (OR) for a low birthweight baby according to maternal and pregnancy characteristics are presented in table 2 . The mean birth weight among singleton full term pregnancies was $3186 \mathrm{~g}$ with an overall proportion of low birth weight $(<2500 \mathrm{~g})$ of $5.0 \%$.

Birth weight was shown to be associated with infant gender, maternal age, maternal education, number of antenatal care visits, parity, and the type of delivery. The relation with maternal age is clearly non-linear with greater risk of a low birthweight child for both very young and older mothers.

Although the analysis was restricted to full term pregnancies, birth weight was still significantly associated with length of gestation (37 to 39 weeks compared with $41+$ weeks). This association was observed first in univariate analyses and persisted in multifactorial models. This variable was thus considered in all multifactorial models.

Multiple regression was used to assess the relation between birth weight and maternal exposure to air pollution allowing for effects of the above variables. To adjust for the potential influence of season on birth weight an indicator variable for month of birth was included. Because of the nonlinear relation between maternal age and birth weight, a nonparametric smooth function of maternal age was fitted in the generalised additive model using a spline function. ${ }^{23}$

The variables "number of antenatal care visits" and "parity" both had a high percentage of missing observations 


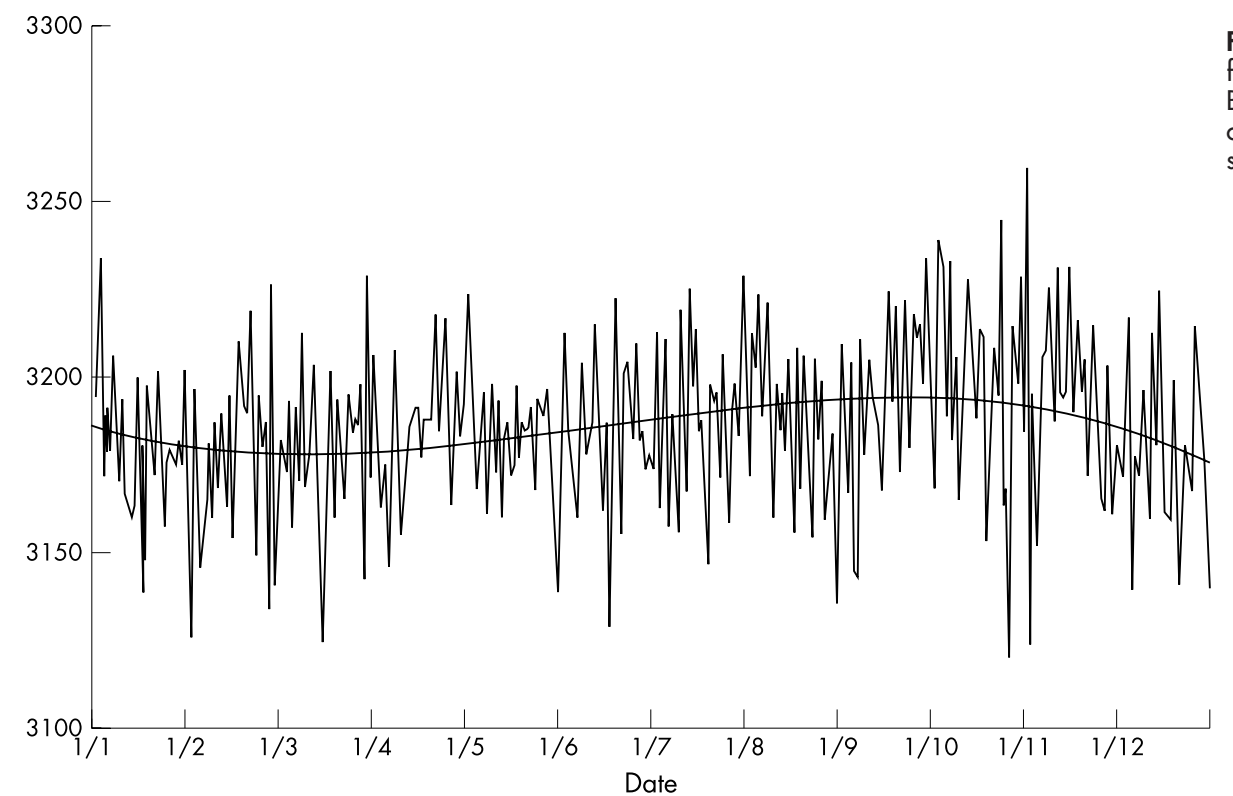

Figure 1 Mean daily birth weight (g) for full term pregnancies in São Paulo, Brazil in 1997. The solid curve is a 4 th order polynomial to highlight the seasonality in birth weight.

(around 30\%). The inclusion of both variables in the same regression model resulted in a high percentage of observations being left out leading to very imprecise estimates. Thus, we decided to include in the final models only the number of antenatal care visits as this variable explained proportionally more of the variation in birth weight than parity. Exploratory analysis modelling both variables at the same time or including just parity all gave similar results.

Table 3 shows the coefficients obtained in GAM regression models for birth weight expressed as changes in mean birth weight according to a $10 \mu \mathrm{g} / \mathrm{m}^{3}$ or a $1 \mathrm{ppm}$ change in exposure to the air pollutants in each trimester of pregnancy. All pollutants exhibited an inverse relation with birth weight when exposure occurred in the first trimester. However, only $\mathrm{PM}_{10}$ and $\mathrm{CO}$ had statistically significant associations. During the second and third trimester results followed different directions and were mostly not significant. Only $\mathrm{SO}_{2}$ exhibited a positive and significant relation with birth weight.

Semi-parametric logistic regression models were then explored again using a smooth function to control for the non-linear effect of maternal age. Levels of air pollutants were divided into quartiles and the lowest quartile $(<25$ th $)$ was used as the reference exposure category. Results of this analysis are shown on table 4. Although generally not significant, results of this analysis showed that the pattern of the association between birth weight and $\mathrm{PM}_{10}$ and $\mathrm{CO}$ during the first trimester was compatible with the results of the GAM regression-that is, an increased risk of a low birthweight baby for higher exposures to air pollutants. The relation between birth weight and exposure to $\mathrm{SO}_{2}$ during the second trimester also exhibited an inverse pattern with higher risk of a low birthweight baby.

The last step was to try and establish which pollutant was responsible for the association with low birth weight. Multiple pollutant models were examined only for the pollutants that showed statistically significant associations in single pollutant linear models-that is, $\mathrm{PM}_{10}, \mathrm{CO}$ and $\mathrm{SO}_{2}$. The rationale for this analysis is that, considering that the pollutants were highly correlated, if one was acting only as a proxy for the other with no contribution of its own, it would be expected that its parameter would be attenuated in a two pollutant model while that of the other would remain relatively unchanged. Results of this analysis are displayed in table 5 .

The inclusion of $\mathrm{PM}_{10}$ and $\mathrm{CO}$ (mean exposure of the first trimester) simultaneously in the same model resulted in a reduction in the coefficient for both pollutants. However, the reduction observed for $\mathrm{CO}(19 \%)$ was proportionally smaller than for $\mathrm{PM}_{10}(61 \%)$. Similar changes happened when $\mathrm{CO}$ and $\mathrm{SO}_{2}$ (mean of the second trimester) were examined together. The coefficients for $\mathrm{PM}_{10}$ and $\mathrm{SO}_{2}$ had smaller decreases when these two pollutants were examined together. In a three pollutant model the decreases in the size of coefficients were greater but still of lesser magnitude for $\mathrm{CO}$. The high correlation between $\mathrm{PM}_{10}$ and $\mathrm{CO}$ (around 0.9) should be noted.

\section{DISCUSSION}

This study found some evidence that maternal exposure to air pollution, especially during the first trimester of pregnancy, is associated with reductions in birth weight. Although it

Table 1 Descriptive statistics for birth weight and air pollution variables according to season in São Paulo, Brazil, 1997

\begin{tabular}{|c|c|c|c|c|c|c|c|}
\hline & \multicolumn{7}{|l|}{ Annual } \\
\hline & Mean (SD) & Min & $\operatorname{Max}$ & Jan-Mar & Apr-Jun & Jul-Aug & Oct-Dec \\
\hline Birth weight (g) & $3185.7(464.3)$ & 1000 & 5500 & $3179.9(464.4)$ & $3183.2(465.1)$ & $3190.4(462.8)$ & 3189.4 (464.5) \\
\hline $\mathrm{PM}_{10}$ & $60.3(25.2)$ & 25.5 & 153.0 & 49.1 (12.2) & $62.7(20.2)$ & 78.4 (34.9) & 50.9 (14.9) \\
\hline $\mathrm{SO}_{2}$ & $19.6(10.3)$ & 3.4 & 56.9 & $22.3(7.7)$ & $28.1(10.1)$ & $17.9(8.7)$ & $10.3(3.9)$ \\
\hline $\mathrm{CO}$ & $3.7(1.6)$ & 1.1 & 11.4 & $2.9(0.8)$ & $3.8(1.3)$ & $4.7(2.2)$ & $3.2(1.0)$ \\
\hline $\mathrm{NO}_{2}$ & $117.9(51.2)$ & 42.5 & 399.6 & $109.3(36.4)$ & $114.4(43.8)$ & $147.2(67.7)$ & $100.6(38.2)$ \\
\hline $\mathrm{O}_{3}$ & $63.0(33.5)$ & 11.7 & 187.6 & $78.0(37.1)$ & $54.0(32.0)$ & $57.6(26.4)$ & $61.6(33.3)$ \\
\hline
\end{tabular}


Table 2 Mean birth weight (SD), proportion of low birth weight (1000 g-2500 g), adjusted odds ratios (OR) and 95\% confidence intervals $(95 \% \mathrm{Cl})$ for low birth weight, for all singleton full term live births in São Paulo, Brazil, 1997

\begin{tabular}{|c|c|c|c|c|c|}
\hline & Number & Missing (\%) & Mean (SD) & LBW (\%) & $O R^{*}(95 \% \mathrm{Cl})$ \\
\hline All live births & 179460 & & $3186(464)$ & 5.0 & - \\
\hline Male & 91793 & 29 & $3244(472)$ & 4.4 & 1.0 \\
\hline Female & 87638 & $(0.02 \%)$ & $3125(448)$ & 5.7 & 1.36 (1.28 to 1.44$)$ \\
\hline \multicolumn{6}{|l|}{ Gestastional week } \\
\hline $37-41$ & 176991 & & $3185(464)$ & 5.1 & 1.79 ( 1.30 to 2.46$)$ \\
\hline $42+$ & 2469 & & 3266 (495) & 3.9 & 1.0 \\
\hline \multicolumn{6}{|l|}{ Maternal age (y) } \\
\hline under 19 & 30112 & & 3125 (449) & 6.0 & 1.07 (0.98 to 1.18$)$ \\
\hline $20-24$ & 51729 & & $3175(450)$ & 4.9 & $0.94(0.86$ to 1.02$)$ \\
\hline $25-29$ & 47462 & 231 & $3212(461)$ & 4.4 & 1 \\
\hline $30-34$ & 32789 & $(0.13 \%)$ & $3217(476)$ & 4.6 & 1.17 (1.06 to 1.28$)$ \\
\hline $35-39$ & 13979 & & $3192(502)$ & 5.9 & 1.40 (1.25 to 1.58$)$ \\
\hline $40+$ & 3158 & & $3182(525)$ & 7.0 & 1.54 (1.25 to 1.91$)$ \\
\hline \multicolumn{6}{|l|}{ Maternal education } \\
\hline none & 2589 & & $3172(511)$ & 6.9 & 1.86 (1.50 to 2.32$)$ \\
\hline $1-4$ & 67652 & & $3183(473)$ & 5.4 & 1.42 (1.25 to 1.62$)$ \\
\hline $4-8$ & 34081 & 30856 & $3181(468)$ & 5.4 & 1.50 (1.32 to 1.72$)$ \\
\hline $8-11$ & 29541 & $(17.2 \%)$ & 3194 (449) & 4.3 & 1.32 (1.15 to 1.51$)$ \\
\hline $12+$ & 14741 & & 3202 (429) & 3.3 & 1.0 \\
\hline \multicolumn{6}{|l|}{ Antenatal care (visits) } \\
\hline none & 3917 & & 3064 (493) & 9.9 & 2.36 (2.08 to 2.68$)$ \\
\hline 1 to 6 & 49145 & 59119 & $3176(471)$ & 5.5 & 1.25 (1.17 to 1.33$)$ \\
\hline $6+$ & 67279 & $(32.9 \%)$ & $3205(452)$ & 4.2 & 1.0 \\
\hline First parity & 53318 & 53018 & $3153(452)$ & 5.4 & $1.32(1.23$ to 1.41$)$ \\
\hline Second or more & 73124 & $(29.5 \%)$ & $3215(474)$ & 4.8 & 1.0 \\
\hline Normal delivery & 85310 & 878 & $3142(455)$ & 5.8 & 1.28 (1.20 to 1.36$)$ \\
\hline Caesarean+forceps & 93272 & $(0.5 \%)$ & $3225(469)$ & 4.3 & 1.0 \\
\hline
\end{tabular}

remains difficult to separate the effect of each pollutant, it appears that $\mathrm{CO}$ and possibly $\mathrm{PM}_{10}$ have an independent and significant negative association with birth weight. On adjusting for infant gender, maternal age, maternal education, antenatal care, type of delivery, month of birth, and seasonal patterns, an increase in mean exposure to $\mathrm{CO}$ of $1 \mathrm{ppm}$ during the first trimester was associated with a reduction of about $23 \mathrm{~g}$ in birth weight. For a $10 \mu \mathrm{g} / \mathrm{m}^{3}$ change in $\mathrm{PM}_{10}$ we observed a $13.7 \mathrm{~g}$ reduction.

There is still a very limited literature regarding effects of air pollution on birth weight and results of these studies are somewhat controversial. While some studies failed to find an effect of air pollution on birth weight, ${ }^{25} 26$ and others have found an effect but with no specification of timing of exposure, ${ }^{827}$ some have found stronger and more consistent effects when exposure occurred during the third trimester, ${ }^{11} 12$ while others found effects in the first trimester. $^{10} 132829$

The possible biological mechanisms involved in the reduction of birth weight associated with maternal exposure to air pollution vary according to the timing of this exposure. The implantation of the fetus and the formation of the placenta occur during the first trimester while weight gain occurs predominantly during the third trimester. ${ }^{30}$ Therefore, exposure during both periods presents the possibility of interference with the final birth weight.

Basic concepts of pathophysiology of fetal growth retardation are based on different levels of maternal supply, fetoplacental competition, and fetal adaptations. In recent studies knowledge about placental development and function

Table 3 Changes in birth weight (in g) for a $10 \mu \mathrm{g} / \mathrm{m}^{3}$ change in exposure to air pollutants (except $\mathrm{CO}$ for which a $1 \mathrm{ppm}$ change was used) at each trimester of pregnancy. Results from regression models adjusted for covariates presented in table 2 (except parity)

\begin{tabular}{llll}
\hline Trimester & Pollutant & \multicolumn{2}{c}{ Change in birth weight $(95 \% \mathrm{Cl})$} \\
\hline First & $\mathrm{PM}_{10}$ & -13.7 & $(-27.0$ to -0.4$)$ \\
& $\mathrm{SO}_{2}$ & -24.2 & $(-55.5$ to 7.1$)$ \\
& $\mathrm{NO}_{2}$ & -7.0 & $(-14.3$ to 0.3$)$ \\
& $\mathrm{CO}_{3}$ & -23.1 & $(-41.3$ to -4.9$)$ \\
Second & $\mathrm{O}_{3}$ & -1.6 & $(-12.8$ to 9.5$)$ \\
& $\mathrm{PM}_{10}$ & -4.4 & $(-18.9$ to 10.1$)$ \\
& $\mathrm{SO}_{2}$ & 33.7 & $(1.6$ to 65.8$)$ \\
& $\mathrm{NO}_{2}$ & 0.3 & $(-8.6$ to 9.2$)$ \\
& $\mathrm{CO}^{\text {Third }}$ & 3.2 & $(-18.2$ to 24.5$)$ \\
& $\mathrm{O}_{3}$ & -0.1 & $(-11.9$ to 11.7$)$ \\
& $\mathrm{PM}_{10}$ & 14.6 & $(0.0$ to 29.2$)$ \\
& $\mathrm{SO}_{2}$ & 9.7 & $(-25.6$ to 44.9$)$ \\
& $\mathrm{NO}_{2}$ & 3.6 & $(-6.6$ to 13.7$)$ \\
& $\mathrm{CO}$ & 1.9 & $(-18.2$ to 22.0$)$ \\
& $\mathrm{O}_{3}$ & -3.0 & $(-15.4$ to 9.4$)$ \\
\hline
\end{tabular}


Table 4 Adjusted odds ratios (OR) and $95 \%$ confidence intervals $(95 \% \mathrm{Cl})$ for low birth weight according to quartiles of air pollution in each trimester of pregnancy, São Paulo, 1997

\begin{tabular}{|c|c|c|c|c|c|c|c|}
\hline \multirow[b]{2}{*}{ Quartile } & & \multicolumn{2}{|c|}{ First trimester } & \multicolumn{2}{|c|}{ Second trimester } & \multicolumn{2}{|c|}{ Third trimester } \\
\hline & & OR & $95 \% \mathrm{Cl}$ & OR & $95 \% \mathrm{Cl}$ & OR & $95 \% \mathrm{Cl}$ \\
\hline \multirow[t]{4}{*}{$\mathrm{PM}_{10}$} & $1 \mathrm{st}$ & 1 & & 1 & & 1 & \\
\hline & 2 nd & 1.105 & (0.994 to 1.229 ) & 1.003 & (0.904 to 1.113 ) & 1.004 & (0.914 to 1.104$)$ \\
\hline & $3 \mathrm{rd}$ & 1.049 & (0.903 to 1.219 ) & 1.074 & (0.920 to 1.254$)$ & 1.003 & $(0.861$ to 1.169 ) \\
\hline & 4 th & 1.144 & $(0.878$ to 1.491$)$ & 1.252 & (1.028 to 1.525 ) & 0.970 & (0.780 to 1.205$)$ \\
\hline \multirow[t]{4}{*}{$\mathrm{CO}$} & $1 \mathrm{st}$ & 1 & & 1 & & 1 & \\
\hline & 2nd & 1.118 & (0.964 to 1.296 ) & 1.032 & (0.889 to 1.184 ) & 0.979 & (0.863 to 1.112 ) \\
\hline & $3 r d$ & 1.069 & (0.905 to 1.262$)$ & 0.978 & (0.836 to 1.144 ) & 0.990 & (0.853 to 1.150 ) \\
\hline & 4 th & 1.022 & $(0.822$ to 1.270$)$ & 1.075 & $(0.888$ to 1.300$)$ & 0.931 & (0.769 to 1.128 ) \\
\hline \multirow[t]{4}{*}{$\mathrm{SO}_{2}$} & $1 \mathrm{st}$ & 1 & & 1 & & 1 & \\
\hline & 2 nd & 0.902 & (0.843 to 0.966$)$ & 0.986 & (0.922 to 1.053 ) & 1.203 & $(0.861$ to 1.680$)$ \\
\hline & $3 r d$ & 0.911 & $(0.819$ to 1.013$)$ & 1.005 & (0.904 to 1.117$)$ & 1.225 & (0.872 to 1.722 ) \\
\hline & 4th & 0.906 & (0.793 to 1.036 ) & 1.017 & (0.883 to 1.173 ) & 1.145 & (0.749 to 1.752 ) \\
\hline \multirow[t]{4}{*}{$\mathrm{NO}_{2}$} & $1 \mathrm{st}$ & 1 & & 1 & & 1 & \\
\hline & 2 nd & 1.060 & $(0.971$ to 1.157$)$ & 0.986 & $(0.902$ to 1.076$)$ & 0.992 & (0.913 to 1.078 ) \\
\hline & $3 r d$ & 1.197 & $(0.885$ to 1.619 ) & 1.008 & $(0.871$ to 1.167$)$ & 1.041 & (0.927 to 1.169 ) \\
\hline & 4 th & 1.126 & $(0.812$ to 1.560$)$ & 1.034 & (0.861 to 1.243 ) & 1.046 & (0.889 to 1.231$)$ \\
\hline \multirow[t]{4}{*}{$\mathrm{O}_{3}$} & $1 \mathrm{st}$ & 1 & & 1 & & 1 & \\
\hline & 2nd & 0.934 & (0.841 to 1.039 ) & 1.094 & (0.969 to 1.236$)$ & 0.877 & (0.775 to 0.992 ) \\
\hline & $3 r d$ & 1.009 & (0.890 to 1.144 ) & 1.099 & (0.945 to 1.278$)$ & 0.991 & (0.859 to 1.144 ) \\
\hline & 4 th & 0.962 & (0.831 to 1.114 ) & 1.116 & (0.939 to 1.326$)$ & 0.976 & (0.826 to 1.153 ) \\
\hline
\end{tabular}

has been increased. ${ }^{31}$ Abnormalities in placental development may occur during its formation, and cellular and molecular functions may be changed leading to inadequate implantation and growth. Abnormalities in placental transport may also develop later on, because of problems in the uteroplacental circulation, exchange at the intervillous space, and umbilical and fetal circulation. All these factors lead to problems with fetal adaptation mechanisms, most importantly decreased fetal growth rate and fetal activities. In the first trimester genetic mutations are considered to be the most important element in placental abnormalities, and in the second and third trimesters extremely complex vascular alterations are considered the main cause of placental abnormalities and consequent fetal growth retardation. Pollutants are recognised as being able to have an effect on both dimensions. ${ }^{31}$

Our finding of a more consistent effect during the first trimester is coherent with this mechanism. Moreover, our results are supported by findings from Seoul, ${ }^{13}$ from the Czech Republic, ${ }^{28}{ }^{29}$ and from a study in the Treplice district of the Czech Republic. ${ }^{10}$ This last study examined exposures during all nine months of pregnancy and revealed that exposure during the first month was the most important for intrauterine growth retardation.

Most air pollutants ( $\mathrm{CO}, \mathrm{SO}_{2}, \mathrm{NO}_{2}$, and particles) have already been described as being associated with reductions in birth weight. But among them, CO and particles have been more consistently found in the few studies published. ${ }^{9-13}{ }^{28}$ As pollutants are highly correlated, it is usually difficult to isolate their effects. We tested multiple pollutant models in the present analysis and found that $\mathrm{CO}$ and $\mathrm{PM}_{10}$ exhibited significant associations that appeared to be independent, with CO presenting a more consistent effect.

Again this finding is coherent with the biological mechanism behind the observed effects as maternal smoking during pregnancy, the environmental factor that best correlates with low birth weight, ${ }^{32}$ also produces $\mathrm{CO}$ which has toxic and ischaemic effects upon fetal growth.

While our results are in accordance with the limited literature regarding effects of air pollution on pregnancy outcomes, some methodological aspects of this study should be discussed. For example, the birth data available for this study came from a system that is known for the completeness and quality of the information provided. However, information on length of gestation was available only in categories ( $<22$ weeks, 22 to 27,28 to 31,32 to 36,37 to 41,42 or more weeks). Although this was not a problem for the definition of term and preterm births, the information on length of gestation was used to calculate the mean exposure to air pollution for each trimester of the pregnancy. Therefore, we should expect a certain degree of inaccuracy in the maternal exposure. However, it is probable that such inaccuracy would be non-differential and any bias introduced would only attenuate the effects found.

In addition, information on important known risk factors for a low birthweight baby such as maternal smoking status, maternal associated morbidity, pre-pregnancy weight, and weight gain were not available. Among these risk factors cigarette smoking is considered the most important predictor of low birth weight. ${ }^{32}$ However, there is some indication that maternal smoking status is associated with maternal education in Brazil ${ }^{33}$ and consequently, adjusting for the last

Table 5 Multiple linear regression coefficients (SE) obtained from single, dual, and three pollutant models, São Paulo, 1997

\begin{tabular}{|c|c|c|c|c|c|}
\hline & $\begin{array}{l}\text { Single pollutant } \\
\text { model }\end{array}$ & $\begin{array}{l}\text { Two pollutant models } \\
\left(\mathrm{PM}_{10} \text { and } \mathrm{CO}\right)\end{array}$ & $\begin{array}{l}\text { Two pollutant models } \\
\left(\mathrm{PM}_{10} \text { and } \mathrm{SO}_{2}\right)\end{array}$ & $\begin{array}{l}\text { Two pollutant models } \\
\text { (CO and } \mathrm{SO}_{2} \text { ) }\end{array}$ & $\begin{array}{l}\text { Three pollutant } \\
\text { models }\end{array}$ \\
\hline $\begin{array}{l}\mathrm{PM}_{10} \\
\mathrm{CO} \\
\mathrm{SO}_{2}\end{array}$ & $\begin{array}{r}0-1.37(0.68) \\
-23.09(9.28) \\
3.37(1.64)\end{array}$ & $\begin{array}{c}-0.51(0.87) \\
-18.68(11.97)\end{array}$ & $-0.94(0.75)$ & $\begin{array}{c}-18.30(11.78) \\
1.37(2.08)\end{array}$ & $\begin{array}{c}-0.47(0.88) \\
-14.58(13.70) \\
1.28(2.09)\end{array}$ \\
\hline
\end{tabular}




\section{Policy implications}

- Current levels of air pollution in the city of São Paulo can produce adverse effects during pregnancy. These effects may be especially important when they contribute to determine low birth weight, one of the strongest predictors of infant mortality

- Exposure to air pollution should be included as a potential risk factor in research on low birth weight and perinatal mortality

- Efforts aimed at mitigating urban air pollution levels in São Paulo can provide benefits to public health

variable contributes to partially adjust for cigarette smoking. In addition, there are no reasons to believe that such risk factors would vary according to levels of air pollution, the exposure of interest in our study. Thus, important confounding effects because of lack of information on such variables is not expected.

An important concern in any epidemiological study is the correct assessment of exposure of the subjects being studied. In our study we defined the exposure of each mother according to citywide levels of air pollution during each trimester of pregnancy.

Firstly, we have the averaged period of three months. It could be argued that a smaller time period would be more appropriate or that a measure that takes into account the variability of air pollution levels during each trimester would better represent the exposure. A study in the Czech Republic ${ }^{10}$ used monthly averages instead of trimesters. However, we could not find any justification for the use of one or the other measurement of exposure. Most of the studies that assessed pregnancy outcomes in relation to air pollution have used trimester exposures. The trimesters represent a traditional time period for the study of the pregnancy period. In addition, any effect of air pollution on birth weight is likely to result from long term exposure to increased levels rather than short term fluctuations. Thus, the mean over trimesters might be a reasonable indicator. Nevertheless, future studies should attempt to explore and compare different indicators of exposure.

A second problem is the fact that each mother was assigned a citywide level of air pollution. It appears that levels of CO can vary considerably across different areas of a city and thus individual exposure could be underestimated or overestimated when averaging levels of all stations. Ritz and $\mathrm{Yu}^{11}$ in their study in Los Angeles assigned the exposure of mothers according to the closest monitoring station to each mother's residence. However, we have to consider the possibility that pregnant women move around different areas of a city for reasons such as working and shopping. Thus, their exposure might not be well represented by just one station. In fact, any approach used for exposure assessment will be subject to error, but this error is likely to be nondifferential and again its main consequence is the attenuation of the effect estimated.

Notwithstanding, this study has the advantage of examining a considerable number of births occurring in a comparatively small area (there are about 200000 births annually in the city of São Paulo, which covers an area of $1509 \mathrm{~km}^{2}$ ). Moreover, besides statistical power and a fairly homogeneous exposure to air pollution, seasonal patterns were taken into account for this analysis. Despite a few caveats, these results are consistent in revealing that exposure to air pollution during pregnancy may interfere with weight gain in the fetus.
Low birth weight is one of the strongest predictors of infant mortality in both developed and developing countries. It is also a more sensitive indicator of environmental effects than late fetal loss or perinatal deaths. Thus, even small effects can be detected in a large population. Therefore, identification of such a widespread risk factor that, to date, has been understudied is very important from the public health perspective. The association between air pollution and birth weight and also other pregnancy outcomes should be confirmed in other locations through well designed studies. Increasing the coherence of this relation will help efforts to minimise human exposure to air pollution in order to protect public health.

\section{Authors' affiliations}

N Gouveia, H M D Novaes, Departamento de Medicina Preventiva, Faculdade de Medicina, Universidade de São Paulo, Brazil

S A Bremner, Department of Community Health Sciences, St George's Hospital Medical School, London, UK

\section{REFERENCES}

1 Committee of the Environmental and Occupational Health Assembly of the American Thoracic Society. Health effects of outdoor air pollution. Am J Respir Crit Care Med 1996;153:3-50.

2 Ballester F, Corella D, Perez-Hoyos S, et al. Air pollution and mortality in Valencia, Spain: a study using the APHEA methodology. J Epidemiol Community Health 1996;50:527-33.

3 Gouveia N, Fletcher T. Time series analysis of air pollution and mortality: effects by cause, age and socioeconomic status. J Epidemiol Community Health 2000;54:750-5.

4 Verhoeff AP, Hoek G, Schwartz J, et al. Air pollution and daily mortality in Amsterdam. Epidemiology 1996;7:225-30.

5 Bobak M, Leon DA. Air pollution and infant mortality in the Czech Republic, 1986-88. Lancet 1992;340:1010-14.

6 Woodruff TJ, Grillo J, Schoendorf KC. The relationship between selected causes of postneonatal infant mortality and particulate air pollution in the United States. Environ Health Perspect 1997; 105:608-12.

7 Pereira LA, Loomis D, Conceicao GM, et al. Association between air pollution and intrauterine mortality in Sao Paulo, Brazil. Environ Health Perspect 1998; 106:325-9

8 Bobak M, Leon DA. Pregnancy outcomes and outdoor air pollution: an ecological study in districts of the Czech Republic 1986-8. Occup Environ Med 1999;56:539-43.

9 Wang X, Ding H, Ryan L, et al. Association between air pollution and low birth weight: a community- based study. Environ Health Perspect 1997; 105:514-20.

10 Dejmek J, Selevan SG, Benes I, et al. Fetal growth and maternal exposure to particulate matter during pregnancy. Environ Health Perspect 1999; 107:475-80.

11 Ritz B, Yu F. The effect of ambient carbon monoxide on low birth weight among children born in southern California between 1989 and 1993. Environ Health Perspect 1999;107:17-25.

12 Maisonet M, Bush TJ, Correa A, et al. Relation between ambient air pollution and low birth weight in the Northeastern United States. Environ Health Perspect 2001;109(suppl 3):351-6.

$13 \mathrm{Ha} \mathrm{EH}$, Hong YC, Lee BE, et al. Is air pollution a risk factor for low birth weight in Seoul? Epidemiology 2001;12:643-8.

14 Rogers JF, Thompson SJ, Addy CL, et al. Association of very low birth weight with exposures to environmental sulfur dioxide and total suspended particulates. Am J Epidemiol 2000;151:602-13.

15 McCormick MC. The contribution of low birth weight to infant mortality and childhood morbidity. N Engl J Med 1985;312:82-90.

16 Hack M, Fanaroff AA. Outcomes of children of extremely low birthweight and gestational age in the 1990's. Early Hum Dev 1999;53:193-218.

17 Kramer MS. Intrauterine growth and gestational duration determinants. Pediatrics 1987;80:502-11.

18 Monteiro C, Benicio M, Ortiz L. Tendência secular do peso ao nascer na cidade de São Paulo (1976-1998). [In portuguese]. Rev Saude Publica 2000;34:26-40.

19 Branum AM, Schoendorf KC. Changing patterns of low birthweight and preterm birth in the United States, 1981-98. Paediatr Perinat Epidemiol 2002; 16:8-15.

20 Keirse MJ. International variations in intrauterine growth. Eur J Obstet Gynecol Reprod Biol 2000;92:21-8.

21 Jorge M, Gotlieb S, Oliveira H. O Sistema de Informação Sobre Nascidos Vivos: primeira avaliação dos dados brasileiro. [In Portuguese]. Informe Epidemiologico do SUS 1996;2:15-48.

22 United Nations Environmental Programme. Urban air pollution in megacities of the world. Oxford: Blackwell Scientific, 1992.

23 Hastie T, Tibshirani R. Generalized additive models. London: Chapman and Hall, 1990. 
24 Dominici F, McDermott A, Zeger SL, et al. On the use of generalized additive models in time-series studies of air pollution and health. Am J Epidemiol 2002; 156: 193-203.

25 Alderman BW, Baron AE, Savitz DA. Maternal exposure to neighborhood carbon monoxide and risk of low infant birth weight. Public Health Rep 1987; 102:410-14.

26 Landgren 0 . Environmental pollution and delivery outcome in southern Sweden: a study with central registries. Acta Paediatr 1996;85:1361-4.

27 Boy E, Bruce N, Delgado H. Birth weight and exposure to kitchen wood smoke during pregnancy in rural Guatemala. Environ Health Perspect 2002;110:109-14.

28 Bobak M. Outdoor air pollution, low birth weight, and prematurity. Environ Health Perspect 2000;108:173-6.
29 Sram RJ, Binkova B, Rossner $P$, et al. Adverse reproductive outcomes from exposure to environmental mutagens. Mutat Res 1999;428:203-15.

30 Mongelli M, Biswas A. A fetal growth standard derived from multiple modalities. Early Hum Dev 2001;60:171-7.

31 Lin CC, Santolaya-Forgas J. Current concepts of fetal growth restriction: part I. Causes, classification, and pathophysiology. Obstet Gynecol 1998;92:1044-55.

32 Fried PA. Prenatal exposure to tobacco and marijuana: effects during pregnancy, infancy, and early childhood. Clin Obstet Gynecol 1993:36:319-37.

33 Barbieri MA, Silva AA, Bettiol $\mathrm{H}$, et al. Risk fsactors for the increasing trend in low birth weight among live births born by vaginal delivery, Brazil. [In Portuguese]. Rev Saude Publica 2000;34:596-602.

\section{THE JECH GALLERY}

\section{Influential women in occupational health} Muriel (Molly) Lina Newhouse, MD: British doyenne of occupational medicine

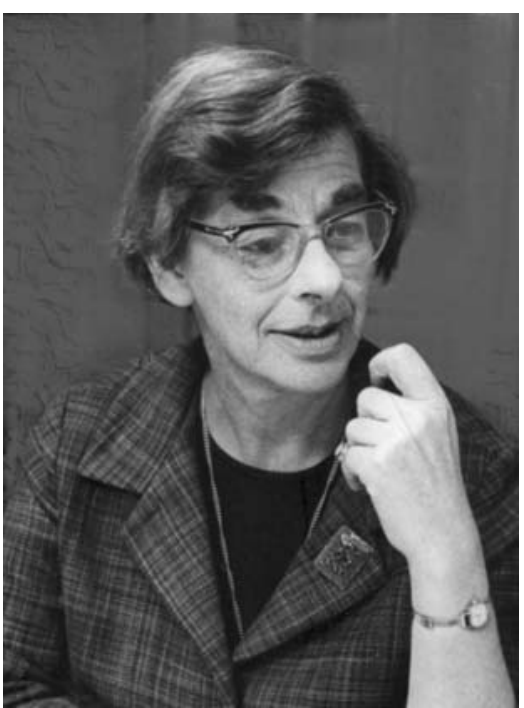

(photo courtesy of Anthony Newhouse)
2 September 1912-15 February 2000

Country of birth: South Africa

D esides nearly 30 years of research on asbestos, Molly Newhouse was an expert on occupational dermatitis, including Dogger Bank Itch, asthma associated with proteolytic enzymes, and respiratory disease among shipyard welders. Her meticulous investigations led indirectly to legislation that banned asbestos.

A pugnacious personality, Newhouse was drafted into the Royal Army Medical Corps, serving in the UK, France, India, and Singapore, and demobilised in 1946, as colonel, the highest rank then attainable for a woman medical officer.

"For every 10 minutes by the bedside, 50 were spent on paperwork."

In 1965, her first published work on mesothelioma outlined occupational a nd domestic exposure to asbestos in the London area (reprinted in 1993, as an example of the best in scientific writing). Newhouse also showed that smoking and asbestos exposure had a multiplicative effect on lung cancer, but no such effect on mesothelioma.

\section{ACKNOWLEDGEMENTS}

The authors gratefully acknowledge the insight and generous contributions of colleagues Geoffrey Berry, William Dixon, David Douglas, Malcolm Harrington, and fa mily Penny Butler, Mrs Margery Corbett, Heather Joshi, and Letty Mooring, for interviews, ob ituaries, and source documents.

D F Salerno

Pfizer Global Research and Development, Ann Arbor Laboratories, Ann Arbor, MI, USA

I L Feitshans Adjunct Faculty, Cornell University, School of Industrial and Labor Relations, Albany, NY, USA

Correspondence to: Deborah F Salerno, 2800 Plymouth Road, Ann Arbor, MI 48 105, USA; deborah.salerno@pfizer.com 